\title{
Colonic polyp histopathology and location in a community-based sample of older adults
}

Heather S. Laird-Fick ${ }^{1 *}$, Gurveen Chahal ${ }^{1}$, Ade Olomu', Joseph Gardiner ${ }^{2}$, James Richard ${ }^{3}$ and Nikolay Dimitrov ${ }^{1}$

\begin{abstract}
Background: Colorectal cancer and its precursors are highly prevalent in developed countries. Estimates in the available literature for prevalence of right-sided-only lesions vary between 20.5 and $48.1 \%$, with association with female gender and advancing age. Since the original polyp studies, premalignant potential of sessile serrated adenomas has been described and screening utilization of colonoscopy in men, women, and older adults has increased. This study describes the histopathology and distribution of colorectal polyps by age and gender in the post-screening era.
\end{abstract}

Methods: A registry of biopsies performed during colonoscopy for adults aged 50+ years in 2002-2012 was created using pathology reports from an independent, regional laboratory. Age, histopathology, and polyp location(s) were included. A subgroup analysis was performed for sessile serrated adenomas for 2007-2012. Distributions of histopathology and polyp location were described by age and gender. Statistical comparisons are made using chi-square tests.

Results: 13,881 patients ( $55.5 \%$ male, $44.5 \%$ female), aged 50-95 years (median $=62$ ) were identified. Most patients (59.9\%) had adenomas. Single and multiple adenomas were more common in men than women (57.7\% vs 42. $3 \%, p<.0001$ and $62.2 \%$ vs $37.8 \%, p<.001)$, and with advancing age $(60.4 \%$ for ages $50-<60,63.4 \%$ for ages $60-<70,65 \%$ for ages $70-<80$, and $68.9 \%$ for ages $>80)$. Villous adenomas ( $n=545 ; 3.6 \%)$, dysplasia $(n=49 ; 0$. $4 \%)$, and invasive carcinoma ( $n=22 ; 0.2 \%)$ were rare. Sessile serrated adenomas were uncommon $(n=417,4.5 \%)$, with greater prevalence in women than men $(5.1 \%$ vs $4 \%, p=0.02)$. Patients aged $70-<80$ were more likely to have multiple polyps than those aged 50- <60 (OR 1.17, $95 \% \mathrm{Cl} 1.03-1.32, p=0.018$ and OR 1.27, $95 \% \mathrm{Cl} 1.10-1$. $46, p=.001)$. Most polyps were from ascending and/or transverse colon $(n=8095 ; 58.3 \%)$. When location was stratified by sex only, men had more polyps than women at each location except the sigmoid and rectum. Further stratification by age of location and sex revealed statistically significant differences (age $50-<60, p<.0001$, age $60-<70, p=.0227$, age 70- $<80, p=.0298$, age 80+, $p=.0018$ ).

Conclusions: This large community-based sample contributes to understanding of colonic neoplasia. The high prevalence of right and transverse lesions supports ongoing use of colonoscopy over sigmoidoscopy for screening examinations.

Keywords: Colon polyps, Sessile serrated adenomas, Colonoscopy, Epidemiology

\footnotetext{
* Correspondence: heather.lairdfick@hc.msu.edu

'Department of Medicine, Michigan State University College of Human

Medicine, East Lansing, MI 48824, USA

Full list of author information is available at the end of the article
} 


\section{Background}

Colorectal cancer is the second leading cause of cancer deaths in the United States (US) [1]. Screening for premalignant colorectal lesions and asymptomatic disease can decrease disease-associated morbidity and mortality. The United States Preventive Services Task Force recommends screening average risk adults aged 50 to 75 years for colorectal cancer using one of several modalities - fecal occult blood, sigmoidoscopy, or colonoscopy [2]. The same tests are recommended for screening higher risk patients, such as those with family history of colorectal cancer, although testing may be offered at younger ages. Continued inclusion of sigmoidoscopy, while controversial among clinicians, is predicated upon a low rate of lesions isolated to the ascending or transverse colon, lower cost, and lower complication rates.

The National Polyp Study, conducted between 1980 and 1990, is the landmark trial which underlies current screening guidelines. Unfortunately, the study's results may not represent the epidemiology of colonoscopy findings in today's general population. Demographics differed; few adults older than age 75 years were included, fewer than half of participants were women, and ethnic minorities were underrepresented [3]. Furthermore, the malignant potential of the sessile serrated polyp was not described until 2007 [4], and therefore some patients at risk for subsequent cancer were likely missed.

In studies from the US and abroad, the distribution of polyps and carcinoma on colonoscopies has varied, with 48.5-60 \% occurring in the left colon and rectum, 20.5$48.1 \%$ on the right and transverse colon, and 24.5$28.7 \%$ with synchronous lesions in both the right and left sided colon [5-8]. Female gender and advancing age have been associated with greater likelihood of rightsided lesions [5]. The reason for the variability of findings is unclear, but might be due to differences in population risks for different countries (e.g. Austria, Saudi Arabia, and the US), inclusion of screening versus diagnostic colonoscopies, or changes in presentation due to ongoing screening efforts.

This study describes the histopathology and distribution of colorectal polyps by age and gender in the post-screening era using a local registry of colonoscopy biopsy samples obtained between 2002 and 2012. A subgroup analysis of sessile serrated adenomas for the years 2007 to 2012 is also reported.

\section{Methods}

A registry of colonoscopy pathology reports for adults, aged 50 to 100 years, obtained between the years 2002 to 2012 was created. Reports were drawn from an accredited, CLIA-certified, independent laboratory specializing in surgical pathology and serving community-based hospitals and surgical centers in the mid-Michigan region. The laboratory employed strict quality controls, including: 1) active review and application of updated histopathological criteria (including that for sessile serrated adenoma), 2) second pathologist confirmation of all reports of carcinoma or advanced neoplasia, and 3) second pathologist review if any uncertainty of the pathologic diagnosis existed.

Cases were defined as all biopsy samples submitted for processing on a single patient for a single date. The registry included the following information: case identifier, date of the procedure, patient date of birth, patient gender, the site within the colon from which the biopsy specimen was taken, and the free text of the histopathology report. Because the reports came from an independent laboratory, additional patient-level data was not available, including demographic information (race/ethnicity, socioeconomic status), and family or personal history of colon cancer or colorectal polyps. Cases were not differentiated based upon indication for the procedure (e.g. screening versus diagnostic testing).

Case data were coded for age at time of procedure (in years), most advanced level of histopathology identified, and region(s) of the colon sampled.

Sessile serrated adenomas (SSAs) were not reported as a distinct entity for the first few years of our registry, but by 2007 the laboratory had firmly established internal criteria and protocols for diagnosing them. Therefore a separate analysis was done for the years 2007 to 2012 . Cases found to have both sessile serrated adenomas and other histological changes (adenoma, villous adenoma, dysplasia, or invasive carcinoma) were included, although they had been coded under the other histology in the primary analysis.

Demographic statistics on colon biopsies by age and gender were summarized using frequencies and percentages. The distribution of histopathology, polyp morphology and polyp location were compared by age and gender by chi-square tests. With multiple versus single histology as outcome, logistic regression was used to assess the association of age and gender, with results summarized by odds ratios and associated $95 \%$ confidence intervals.

The de-identified clinical dataset supporting the conclusions of this article is available upon request to the corresponding author.

The study was approved as exempt by the Michigan State University institutional review board (IRB \# x121297e).

\section{Results}

A total of 13,881 patients had one or more biopsy specimens taken during colonoscopies that showed polyp(s) or invasive carcinoma. A total of 7,705 (55.5\%) were 
Table 1 Distribution of Sex by Age among 13,881 patients

\begin{tabular}{lllll}
\hline Age & Total $^{b}, \mathrm{n}(\%)$ & Sex $^{\mathrm{a}}$ & p-value \\
\cline { 3 - 4 } & & Female, n (\%) & Male, n (\%) & \\
\hline $50-<60$ & $5828(42.0)$ & $2509(43.1)$ & $3319(57.0)$ & $<.0001$ \\
$60-<70$ & $4636(33.4)$ & $2048(44.2)$ & $2588(55.8)$ & $<.0001$ \\
$70-<80$ & $2751(19.8)$ & $1251(45.5)$ & $1500(54.5)$ & $<.0001$ \\
$80-95$ & $666(4.8)$ & $368(55.3)$ & $298(44.7)$ & 0.007 \\
Overall & $13881(100.0)$ & $6176(44.5)$ & $7705(55.5)$ & $<.0001$ \\
Mean (SD), years & $62.8(9.2)$ & $63.3(9.5)$ & $62.5(8.9)$ & $<.0001$
\end{tabular}

apercent in row might not sum to 100 due to rounding. Chi-square tests compare

sex distribution by age category, and overall. Mean ages compared by Wilcoxon test

${ }^{\text {bPercent }}$ of all patients $(n=13,881)$

male and 6,176 (44.5\%) female. Ages ranged from 50 to 95 years, with a mean (SD) of 62.8 (9.2) years and median of 62 years. Females were slightly older (mean age 63.3 years) than males (mean age 62.5 years) and due to the large sample size, the difference was significant $(p<.0001)$. Differences in gender were seen in each age category (Table 1).

\section{Histopathology}

Adenomatous polyps, whether singular or multiple, were the most common pathological finding ( $n=8,305 ; 59.9 \%)$, followed by hyperplastic polyps ( $n=4,600 ; 33.1 \%)$. In contrast, villous adenomas $(\mathrm{n}=545 ; 3.6 \%)$, moderate to high grade dysplasia $(n=49 ; 0.4 \%)$ and invasive carcinoma $(n=22 ; 0.2 \%)$ were rare (Table 2$)$.
Typical adenomas, whether single or multiple, were more common among males $(n=4920 ; 63.9 \%)$ than females $(n=3385 ; 54.9 \%) \quad(p<.0001$ for comparison). Single hyperplastic polyps more common among women $(n=1699 ; 51.6 \%)$ than men $(n=1597 ; 48.4 \%) \quad(p=$ 0.077); there was no significant difference by sex for multiple hyperplastic polyps $(p=0.580)$ (Fig. 1, Table 2).

Trends in histopathology based on age were seen as well. Adenomas were the most common finding across all age groups, and prevalence increased with increasing age (Fig. 2).

Between 2007 and 2012, SSAs were found in a total of 417 patients (4.5\%), (Table 3). There was no statistical difference by sex, in overall SSA or within SSA types. However, amongst all 9301 patients, prevalence of SSA was higher in females $(n=215 ; 5.1 \%)$ than in males $(n=$ $202 ; 4.0 \%)(p=0.02)$. Prevalence of SSA was also greater in patients ages $50-<60$ years than older adults $(7.6 \%$ versus $2.0-4.3 \% . p<.0001$ for distribution of histology by age) as seen in Fig. 2.

\section{Number of polyps}

Polyps were classified as single or multiple in the registry. The prevalence of multiple polyps was higher in men $(n=2,735 ; 35.5 \%)$ than in women $(n=1,978$; $32.0 \%), p<.0001$. Multiple polyps were also more common with increasing age: age 50-59 years, 32.3\%; 60-69 years, $34.3 \%$; 70-79 years, $36.5 \%$; and $80+$ years, $35.7 \%$ $(p=.001)$. Using age $50-59$ years and sex as referent categories, the odds of having multiple (vs single) polyps

Table 2 Distribution of Sex by Histology among 13,881 patients

\begin{tabular}{|c|c|c|c|c|}
\hline \multirow[t]{2}{*}{ Histopathology } & \multirow{2}{*}{$\begin{array}{l}\text { Total }^{\mathrm{b}} \\
\text { n (\%) }\end{array}$} & \multicolumn{2}{|l|}{$\operatorname{Sex}^{a}$} & \multirow[t]{2}{*}{ p-value } \\
\hline & & $\begin{array}{l}\text { Female } \\
\mathrm{n}(\%)\end{array}$ & $\begin{array}{l}\text { Male } \\
\text { n (\%) }\end{array}$ & \\
\hline Hyperplastic, single & $3296(23.7)$ & $1699(51.6)$ & $1597(48.4)$ & 0.077 \\
\hline Adenoma, single & $5449(39.3)$ & $2307(42.3)$ & $3142(57.7)$ & $<.0001$ \\
\hline Villous adenoma, single & $175(1.3)$ & $73(41.7)$ & $102(58.3)$ & 0.028 \\
\hline Sessile serrated adenoma, single & 215 (1.6) & $109(50.7)$ & $106(49.3)$ & 0.838 \\
\hline Dysplasia, single & $23(0.2)$ & $6(26.1)$ & $17(73.9)$ & 0.022 \\
\hline Invasive carcinoma, single & $10(0.1)$ & $4(40.0)$ & $6(60.0)$ & 0.527 \\
\hline Hyperplastic, multiple & $1304(9.4)$ & $662(50.8)$ & $642(49.2)$ & 0.580 \\
\hline Adenoma, multiple & $2856(20.6)$ & $1078(37.8)$ & $1778(62.2)$ & $<.0001$ \\
\hline Villous adenoma, multiple & $370(2.3)$ & $149(40.3)$ & $221(59.7)$ & 0.0002 \\
\hline Sessile serrated adenoma, multiple & $145(1.0)$ & $78(53.8)$ & $67(46.2)$ & 0.361 \\
\hline Dysplasia, multiple & $26(0.2)$ & $5(19.2)$ & $21(80.8)$ & 0.002 \\
\hline Invasive carcinoma, multiple & $12(0.1)$ & $6(50.0)$ & $6(50.0)$ & 1.00 \\
\hline Overall single & $9168(66.1)$ & 4198 (45.8) & $4970(54.2)$ & $<.0001$ \\
\hline Overall multiple & $4713(34.0)$ & $1978(42.0)$ & 2735 (58.0) & $<.0001$ \\
\hline Total & 13881 (100.0) & $6176(44.5)$ & 7705 (55.5) & $<.0001$ \\
\hline
\end{tabular}

a Percent in row might not sum to 100 due to rounding. ${ }^{\mathrm{b}}$ Percent of total patients 


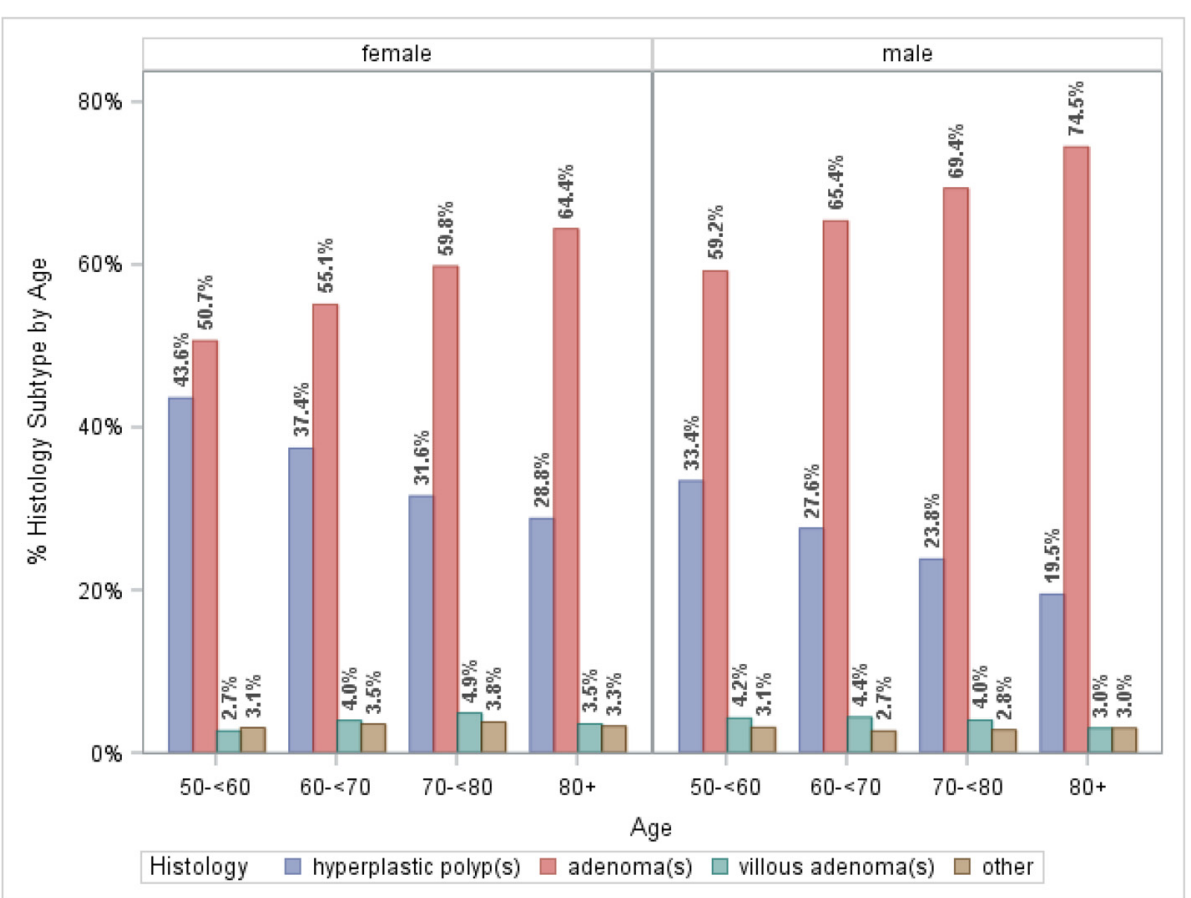

Fig. 1 Distribution of histology by age stratified by sex. Comparisons of the distribution of polyp histology by sex in each age group were significant: Age 50- $<60$ years, $p<.0001$; age 60- $<70$ years, $p<.0001$; age $70-<80, p<.0001$; age $80+$ years, $p=.0379$

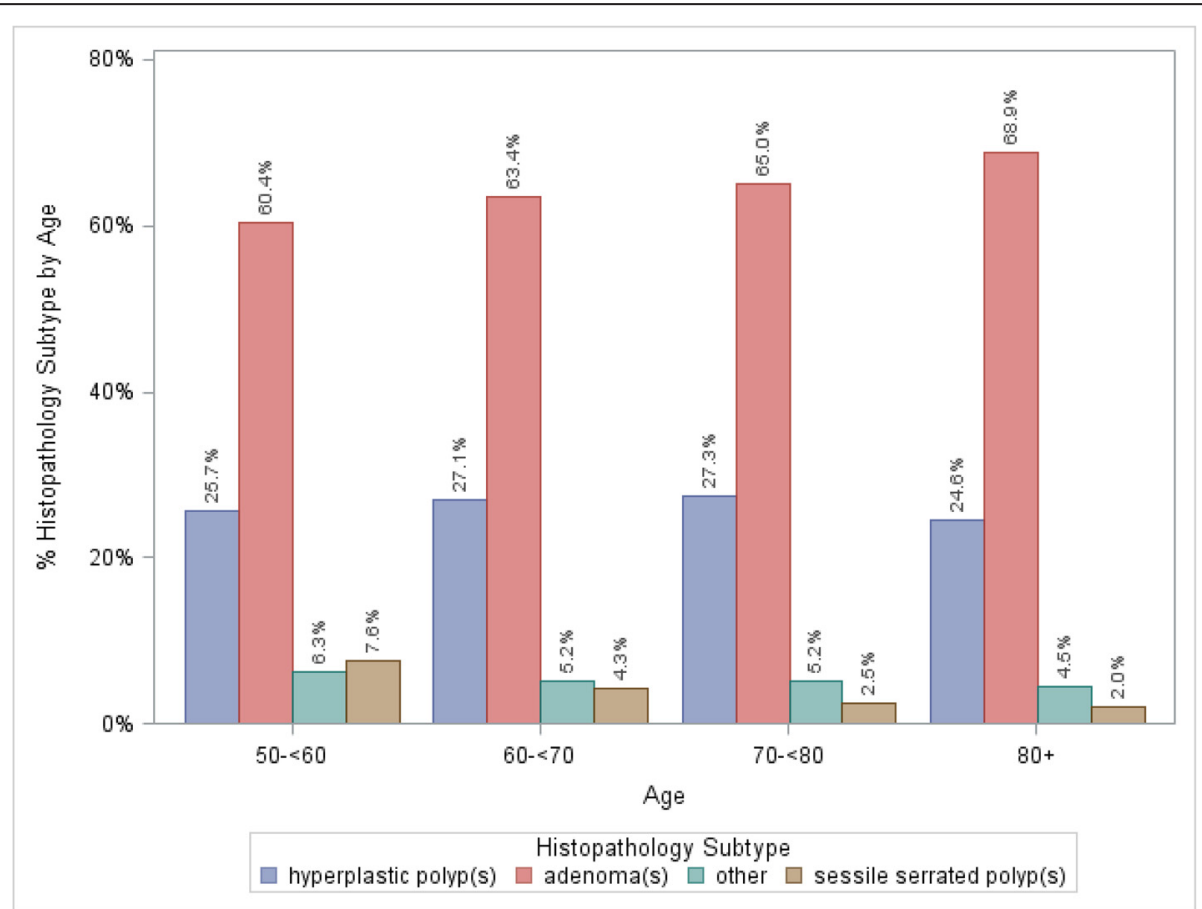

Fig. 2 Distribution of histology by age for subgroup analysis, 2007-2012. $p<.0001$ for distribution of histology across age groups 
Table 3 Prevalence of sessile serrated adenomas, 2007-2012 in 9301 patients

\begin{tabular}{lllll}
\hline Histology & $\begin{array}{l}\text { Total }^{\mathrm{a}} \\
\mathrm{n}(\%)\end{array}$ & \begin{tabular}{l} 
Sex \\
\cline { 3 - 4 }
\end{tabular} & $\begin{array}{l}\text { Female } \\
\mathrm{n}(\%)\end{array}$ & $\begin{array}{l}\text { Male } \\
\mathrm{n}(\%)\end{array}$ \\
\hline Solitary & $215(2.3)$ & $109(50.7)$ & $106(49.3)$ & 0.838 \\
Multiple & $145(1.6)$ & $78(53.8)$ & $67(46.2)$ & 0.361 \\
SSA Other & $57(0.6)$ & $28(49.1)$ & $29(50.9)$ & 0.895 \\
Overall & $417(4.5)$ & $215(51.6)$ & $202(48.4)$ & 0.524 \\
Non SSA & $8884(95.5)$ & $4016(45.2)$ & $4868(54.8)$ & $<.0001$
\end{tabular}

${ }^{\text {aPercent }}$ of patients $(n=9301)$

was higher at older age, while female sex had lower odds relative to males (Table 4). Both age and sex effects were significant; an age by sex interaction was not found.

\section{Location}

More than half the patients had biopsy specimens isolated within either the right colon $(n=3,943 ; 28.4 \%)$, the transverse colon $(n=3,288 ; 23.7 \%)$, or a combination of the two $(n=864 ; 6.2 \%)$ (Table 5$)$ - regions beyond the reach of a sigmoidoscope. Only $29.1 \%$ of patients had specimens isolated to the left side of the colon: left colon $(n=1,379 ; 9.9 \%)$, sigmoid colon $(n=$ $2,382 ; 17.2 \%)$, rectum $(n=94 ; 0.7 \%)$, or a combination of these sites $(n=180 ; 1.3 \%)$. A minority of patients $(n=1,607 ; 11.6 \%)$ had polyps on both the left side of

Table 4 Odds ratios and $95 \%$ confidence intervals for association of age with multiple versus single polyp classification in 13,881 patients

\begin{tabular}{|c|c|c|c|c|c|}
\hline & $\begin{array}{l}\text { Histology } \\
\text { Frequency }\end{array}$ & $\begin{array}{l}\text { Odds } \\
\text { Ratio }\end{array}$ & \multicolumn{2}{|c|}{$\begin{array}{l}95 \% \text { Confidence } \\
\text { Limits }\end{array}$} & \multirow[t]{2}{*}{ p-value } \\
\hline & \multicolumn{4}{|l|}{ Multiple/Single } & \\
\hline \multicolumn{6}{|l|}{ Females: Age } \\
\hline $50-<60$ referent & $755 / 1754$ & 1.00 & & & \\
\hline $60-<70$ & $659 / 1389$ & 1.10 & 0.97 & 1.25 & 0.130 \\
\hline $70-<80$ & $441 / 810$ & 1.27 & 1.10 & 1.46 & 0.001 \\
\hline $80-95$ & $123 / 245$ & 1.17 & 0.92 & 1.47 & 0.195 \\
\hline \multicolumn{6}{|l|}{ Males: Age } \\
\hline $50-<60$ referent & $1127 / 2192$ & 1.00 & & & \\
\hline $60-<70$ & $931 / 1657$ & 1.09 & 0.98 & 1.22 & 0.106 \\
\hline $70-<80$ & $562 / 938$ & 1.17 & 1.03 & 1.32 & 0.018 \\
\hline $80-95$ & $115 / 183$ & 1.22 & 0.96 & 1.56 & 0.107 \\
\hline \multicolumn{6}{|l|}{ Adjusted $^{a}$} \\
\hline Male referent & $2735 / 4970$ & 1.00 & & & \\
\hline Female & 1978/4198 & 0.85 & 0.79 & 0.91 & $<.0001$ \\
\hline Age, 5 yr increase & $\ldots$ & 1.05 & 1.03 & 1.07 & $<.0001$ \\
\hline
\end{tabular}

${ }^{\mathrm{a} E s t i m a t e s}$ from multiple logistic regression with Sex and Age the colon and either the ascending or transverse colon. Information about the site of the biopsy specimen was missing for 144 patients $(1.0 \%)$. There was a small but statistically significant difference in distribution by gender and age (Fig. 3).

\section{Discussion}

In this community based sample of adults aged 50 and older, adenomas were the most common histopathological finding $(n=8,305 ; 59.9 \%)$, with higher prevalence in males $(p<.0001)$ and increasing prevalence by age in either sex $(p<.0001)$.

Isolated hyperplastic polyps were the second most common finding ( $n=4,600 ; 33.1 \%)$. The presence of multiple polyps was positively associated with male sex $(p<.0001)$ and increasing age $(p=.001) .58 .3 \%$ of patients had no lesions within reach of a typical sigmoidoscope; while there were statistically significant differences in polyp location based on age and gender, the absolute differences were small and unlikely to be of clinical significance.

These results differ from previous reports in several important ways. Most studies have reported a preponderance of left-sided polyps $[5,6,8]$, with right-sided ones more common in women [5]. In contrast, most patients in this study had right-sided polyps, regardless of gender and age. In addition, few patients $(n=22 ; 0.2 \%)$ in this registry had invasive carcinoma, validating results from Odom et al who reported a $0.3 \%$ rate of invasive carcinoma in single community hospital between 1999 and 2002 [9]. Other studies have found higher rates, ranging from $1.1 \%$ in a prospective four year screening study in Austria [6], to $6 \%$ in the enrollment phase of the National Polyp Study [3]. In contrast to Odom et al, this study found more villous adenomas (3.6\%, versus $1.0 \%$ ) [9], and provides data on sessile serrated adenomas.

Information about the epidemiology of SSAs is limited. Prevalence has been reported between $0.6-13.8 \%$ of resected polyps $[7,10,11]$. Coexisting adenomatous polyps were found in nearly half of patients in one series [11]. The present study found an intermediate prevalence (4.5\%); $86.3 \%$ of these patients did not have other adenomatous polyp types present. Some studies [7, 10], but not all [11], have reported a female preponderance. This study found no statistical difference by sex, in overall SSA or within SSA types. However, amongst all 9301 patients, prevalence of SSA was higher in females $(n=215 ; 5.1 \%)$ than in males $(n=202 ; 4.0 \%)(p=0.02)$.

This study has numerous strengths. It utilized a large, community based sample with inclusion of significant numbers of women and older adults. Experts in surgical pathology interpreted all specimens, and their reports provided greater detail than available through most epidemiologic studies. Limitations include lack of information about the race/ethnicity of patients, or the indications for 
Table 5 Distribution of polyps by location among 13,881 patients

\begin{tabular}{|c|c|c|c|c|c|}
\hline \multirow[t]{2}{*}{ Location } & \multirow{2}{*}{$\begin{array}{l}\text { Distance from rectum } \\
\text { (in centimeters) }\end{array}$} & \multirow{2}{*}{$\begin{array}{l}\text { Total } \\
\text { n (\%) }\end{array}$} & \multicolumn{2}{|l|}{$\mathrm{Sex}^{\mathrm{a}}$} & \multirow[t]{2}{*}{ p-value } \\
\hline & & & $\begin{array}{l}\text { Female } \\
\mathrm{n}(\%)\end{array}$ & $\begin{array}{l}\text { Male } \\
\text { n (\%) }\end{array}$ & \\
\hline Right & $132-147$ & $3943(28.4)$ & $1842(46.7)$ & $2101(53.3)$ & $<.0001$ \\
\hline Transverse and flexures & $82-132$ & $3288(23.7)$ & $1351(41.1)$ & $1937(58.9)$ & $<.0001$ \\
\hline Ascending and transverse & $\mathrm{n} / \mathrm{a}$ & $864(6.2)$ & $330(38.2)$ & $534(61.8)$ & $<.0001$ \\
\hline Left & $57-82$ & $1379(9.9)$ & $645(46.8)$ & $734(53.2)$ & 0.017 \\
\hline Sigmoid & $15-57$ & $2382(17.2)$ & $1178(49.5)$ & $1204(50.6)$ & 0.594 \\
\hline Rectum & 4 to 14 & $94(0.70)$ & $48(51.1)$ & $46(48.9)$ & 0.837 \\
\hline Left and (transverse or ascending) & n/a & 1607 (11.6) & $638(39.7)$ & $969(60.3)$ & $<.0001$ \\
\hline Left and sigmoid & $\mathrm{n} / \mathrm{a}$ & $180(1.3)$ & $76(42.2)$ & $104(57.8)$ & 0.037 \\
\hline Not specified & $\mathrm{n} / \mathrm{a}$ & $144(1.0)$ & $68(47.2)$ & $76(52.8)$ & 0.510 \\
\hline Total & & $13881(100.0)$ & $6176(44.5)$ & $7705(55.5)$ & $<.0001$ \\
\hline
\end{tabular}

${ }^{\mathrm{a}}$ Percent in row might not sum to 100 due to rounding. ${ }^{\mathrm{b}}$ Percent of total patients

individual studies (i.e. diagnosis in symptomatic patients, screening for average or high risk, or surveillance with personal history of polyposis). Some patients may have also been included more than once, if they underwent repeat colonoscopies in the ten year period.

\section{Conclusions}

Right-sided and transverse polyps were more common in this community-based registry than previously reported, supporting whole-colon screening (e.g. colonoscopy) as opposed to regional evaluation (e.g. sigmoidoscopy). Invasive carcinoma was rare, but villous adenomas more common than in another community-based study [9]. Sessile serrated adenomas were uncommon $(n=417,4.5 \%)$, with greater prevalence in women than men (5.1\% vs $4 \%, p=0.02)$ and adults aged $50-<60$ years (Fig. 2), warrant endoscopist vigilance for flat lesions in these populations.

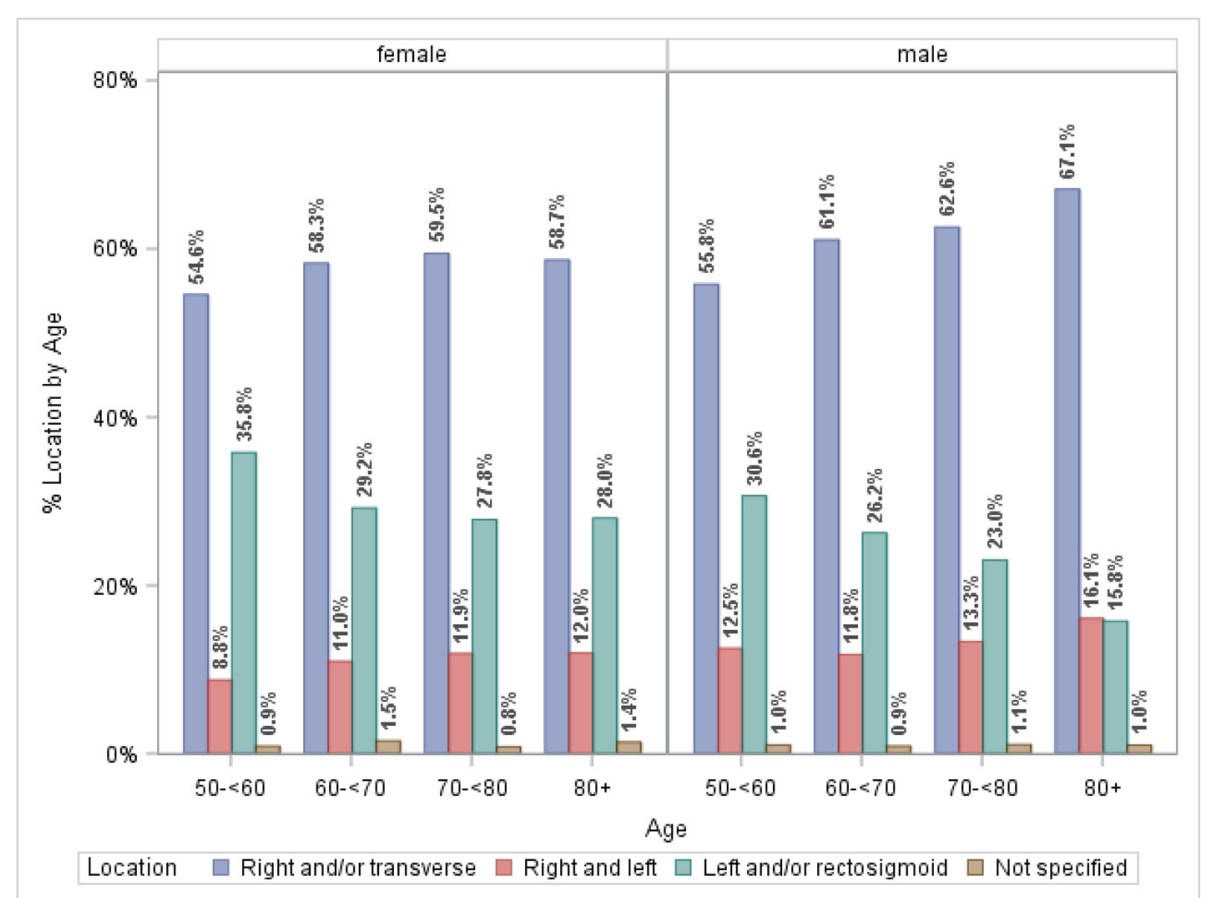

Fig. 3 Distribution of polyp location by age stratified by sex. In each age group, there are statistically significant differences of the distribution of location by sex. Age 50- $<60$ years, $p<.0001$; age 60- $<70$ years, $p=.0227$; age $70-<80$ years, $p=.0298$; age 80+ years, $p=.0018$ 


\section{Abbreviations}

SD, Standard Deviation; SSA, Sessile serrated adenoman; US, United States

\section{Acknowledgements}

Not applicable

\section{Funding}

None

\section{Availability of data and material}

The datasets analysed during the current study are available from the corresponding author on reasonable request.

\section{Authors' contributions}

HSLF participated in design of the study, coding and interpretation of the data. GC participated in coding and interpretation of the data. JG analyzed and interpreted the patient data. JR was one of the pathologists interpreting the polyp specimens. ND participated in design of the study and interpretation of the data. All authors were major contributors in the writing of the manuscript; read and approved the final manuscript; and agreed to be accountable for all aspects of the work

\section{Authors' information}

HSLF is a board-certified general internist with clinical expertise in the care of aging adults and research interest in cancer in the elderly.

GC is an internal medicine resident at Michigan State University.

AO practiced gastroenterology in the United Kingdom before immigrating

to the United States and practicing as a board-certified general internist. She is the Vice Chair for Research in the Dept. of Medicine at Michigan State University, with expertise in community based research on secondary prevention.

$J R$ is a board-certified pathologist and the medical director of Pathology at EW Sparrow Hospital and Sparrow CAP-Lab from which the data for the study are derived. He has served as a member of the boards of the College of American Pathologists, the Michigan Society of Pathologists, the Michigan Hospital Association (MHA) Keystone Center, the MHA Patient Safety

Organization, the Michigan State Medical Society, and the Ingham County Medical Society.

JG is a professor and former Chairperson of the Dept. of Epidemiology at Michigan State University. He has published extensively in oncology and other subspecialty fields.

ND is professor emeritus of hematology/oncology at Michigan State

University, remaining engaged in research and mentorship of investigators.

\section{Competing interests}

The authors declare that they have no competing interests.

\section{Consent for publication}

Not applicable

\section{Ethics approval and consent to participate}

The study was approved as exempt by the Michigan State University institutional review board (IRB \# x12-1297e); consent was not required per IRB.

\section{Author details}

'Department of Medicine, Michigan State University College of Human Medicine, East Lansing, MI 48824, USA. ²Department of Epidemiology and Biostatistics, Michigan State University College of Human Medicine, East Lansing, MI 48824, USA. ${ }^{3}$ Department of Pathology, EW Sparrow Hospital, CAP-Labs, Lansing, Ml 48912, USA.

Received: 28 December 2015 Accepted: 21 July 2016

Published online: 02 August 2016

\section{References}

1. SEER Cancer Statistics Factsheets: Colon and Rectum Cancer. [http://seer.cancer. gov/statfacts/html/colorect.html]. Accessed 24 July 2016

2. Colorectal Cancer: Screening (2016) [http://www uspreventiveservicestaskforce.org/Page/Document/UpdateSummaryFinal/ colorectal-cancer-screening2]. Accessed 25 July 2016.
3. Winawer SJ, Zauber AG, O'Brien MJ, Gottlieb LS, Sternberg SS, Stewart ET, Bond JH, Schapiro M, Panish JF, Waye JD, Kurtz RC, Shike M, Ho MN. Workgroup* TNPS: Design, Methods, and Characteristics of Patients with Newly Diagnosed Polyps. Cancer. 1992;70:1236-45.

4. Khalid O, Radaideh S, Cummings OW, O'Brien MJ, Goldblum JR, Rex DK. Reinterpretation of histology of proximal colon polyps called hyperplastic in 2001. World J Gastroenterol. 2009;15:3767-70.

5. McCashland TM, Brand R, Lyden E, De Garmo P. Gender differences in colorectal polyps and tumors. Am J Gastroenterol. 2001;96:882-6.

6. Ferlitsch M, Reinhart K, Pramhas S, Gal O, Bannert C, Dunkler D, Almadi M, Azzam N, Wadera J, Sadaf N, Alharbi O, Aljebreen A, Carr NJ, Mahajan H, Tan KL, Hawkins NJ, Ward RL. in Individuals Undergoing Screening Colonoscopy. Saudi J Gastroenterol. 2014;62:516-8.

7. Carr NJ, Mahajan H, Tan KL, Hawkins NJ, Ward RL. Serrated and non-serrated polyps of the colorectum: their prevalence in an unselected case series and correlation of BRAF mutation analysis with the diagnosis of sessile serrated adenoma. J Clin Pathol. 2009:62:516-8.

8. Almadi M, Azzam N, Wadera J, Sadaf N, Alharbi O, Aljebreen A. Prevalence and characteristics of colonic polyps and adenomas in 2654 colonoscopies in Saudi Arabia. Saudi J Gastroenterol. 2014:20:154.

9. Odom SR, Duffy SD, Barone JE, Ghevariya V, McClane SJ. The rate of adenocarcinoma in endoscopically removed colorectal polyps. Am Surg. 2005;71:1024-6

10. Abdeljawad K, Vemulapalli KC, Kahi CJ, Cummings OW, Snover DC, Rex DK. Sessile serrated polyp prevalence determined by a colonoscopist with a high lesion detection rate and an experienced pathologist. Gastrointest Endosc. 2014;81:517-24.

11. Gurudu SR, Heigh RI, de Petris G, Heigh EG, Leighton JA, Pasha SF, Malagon IB, Das A. Sessile serrated adenomas: Demographic, endoscopic and athological characteristics. World J Gastroenterol. 2010;16:3402-5.

\section{Submit your next manuscript to BioMed Central and we will help you at every step:}

- We accept pre-submission inquiries

- Our selector tool helps you to find the most relevant journal

- We provide round the clock customer support

- Convenient online submission

- Thorough peer review

- Inclusion in PubMed and all major indexing services

- Maximum visibility for your research

Submit your manuscript at www.biomedcentral.com/submit 